\title{
Risiko in Kinderschuhen
}

\section{Iris Ritzmann}

Prof. Dr. med. et lic. phil., Mitglied der Redaktion Medizingeschichte

«Das Beste für uns Kinder war ein Pedoskop am Ende des Ladens", berichtet der Fotograf Michael Deschamps im Januar 2019 auf seiner Website augenschmaus.athost.de. Das Pedoskop macht durch einen Röntgenapparat das Fussskelett innerhalb von Schuhen sichtbar. In erster Linie sollte der Apparat Eltern den Kauf von Kinderschuhen erleichtern. Durch die oben ausgeschnittenen Sehöffnungen beurteilten Eltern, Ladenpersonal und das Kind selbst, ob die neuen Modelle genügend Platz für die Zehen liessen. Deschamps erinnert sich, wie sich die älteren Kinder vergnügten, das eigene «Fussskelett im Röntgenbild tanzen zu sehen». In den 1950er Jahren stand in jedem grösseren Schuhgeschäft ein Pedoskop. Da Kinderfüsse ständig wachsen, waren in der Regel zahlreiche Besuche im Schuhgeschäft notwendig.

\section{Medizinische Deutung des Alltags}

Das gezeigte Objekt wurde in Uelzen von der Firma Wilhelm Altenkirch \& Sohn hergestellt und stand über Jahre als Leihgabe im Hamburger Medizinhistorischen Museum, bevor es wieder zurück in die Bestände des Technikmuseums Electrum in Hamburg gelangte. Wie Messungen in den späten 1940er Jahren ergaben, war die Strahlenbelastung durch diese Geräte enorm hoch.

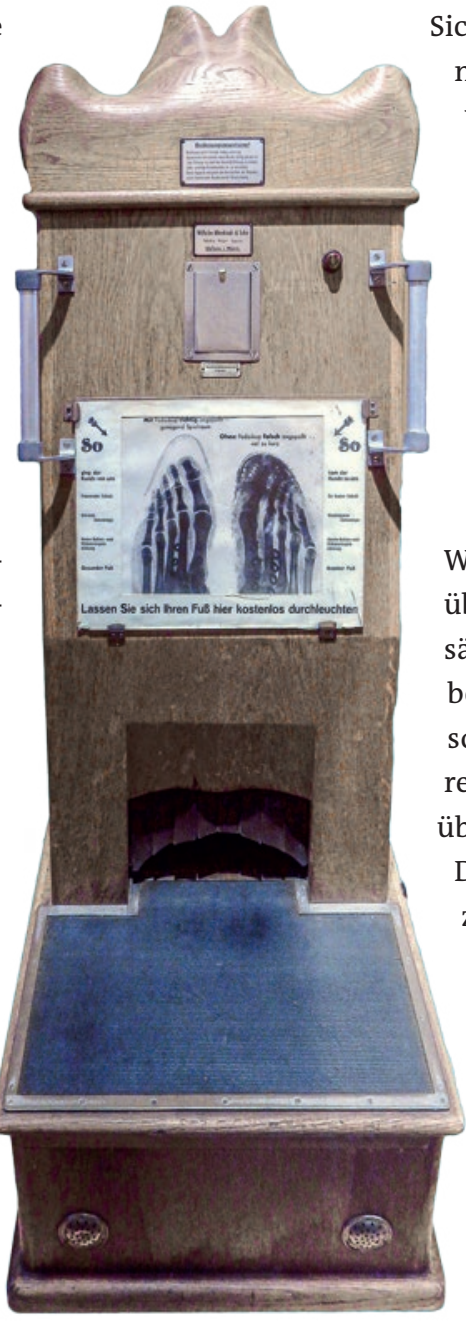
Das Pedoskop konnte sich im Rahmen einer immer umfassenderen medizinischen Deutung des Alltags etablieren. Wie die Schweizer Historikerin Monika Dommann in ihrer Geschichte der Röntgenstrahlen von 2003 darlegt, wurde der Schuhkauf mit diesem Apparat zur medizinischen Untersuchung, der Kinder- fuss zum wissenschaftlichen Objekt. Das Bild der Fussknochen versprach eine Objektivität, die der eigenen Wahrnehmung eines unbequemen Schuhs weit überlegen zu sein schien. Die radiologischen Methoden fes-

tigten die Vorstellung einer unverzichtbaren, Sicherheit versprechenden und hochmodernen Gesundheitstechnologie, was sich parallel in der Präventivmedizin verfolgen lässt, etwa in den Reihendurchleuchtungen bzw. Schirmbildkontrollen der Schulkinder oder routinemässigen radiologischen Uterusuntersuchungen von Schwangeren.

\section{Das eigene «Fussskelett im Röntgenbild tanzen sehen".}

Warum gab es kaum Bedenken gegenüber einer Bestrahlung, die doch hauptsächlich Kinder betraf? Immerhin berichteten nicht nur Fachjournale, sondern auch zahlreiche Medien bereits in den 1920er Jahren ausführlich über die Risiken von Röntgenstrahlen. Das Gefahrenpotenzial schien nicht zum Bild einer hochmodernen Medizin zu passen. Erst zehn Jahre nach dem Abwurf der ersten Atombomben - der Bundesrat diskutierte damals über eine atomare Aufrüstung der Schweiz - erliess das Eidgenössische Gesundheitsamt erste Richtlinien für Strahlenschutz, im Herbst 1963 auch für «Schuhdurchleuchtungsapparate». Dennoch sollte es noch Jahre dauern, bis das Pedoskop verschwand und wieder Langeweile im Schuhgeschäft aufkam.

\section{Bildnachweis}

Pedoskop der Firma Wilhelm Altenkirch \& Sohn, Uelzen. Sammlung des Museums Electrum, Hamburg. Foto: Iris Ritzmann 2015. 